\title{
ANALISIS TINGKAT TECHNOPRENEURSHIP PADA UMKM SAMBEL PECEL WAHYU TUMURUN KOTA MADIUN
}

\author{
Ramadhan Prasetya Wibawa ${ }^{1)}$, Dyan Kharisma Nurdiansyah ${ }^{2)}$, Suci Romelah ${ }^{3)}$ \\ Pendidikan Ekonomi FKIP UNIVERSITAS PGRI MADIUN \\ ramadhan@unipma.ac.id ${ }^{11}$, dyan.kharisma20@gmail.com ${ }^{21}$, suciromelah98@gmail.com $^{\text {3) }}$
}

\begin{abstract}
Madiun city is one of the cities located in the East Java region that has a typical food that is "Sambel Pecel". One of the most famous pecel sambel in Madiun City is sambel pecel Wahyu Tumurun. UMKM sambel pecel Wahyu Tumurun is one of the excellent products of Madiun city. There needs to be a technopreneursip level analysis at UMKM sambel pecel Wahyu Tumurun of Madiun City in order to improve the results and the quality development of the undertakings, so as to be able to compete in the global market. The research was conducted by using qualitative descriptive research method. Data collection technique is done by observation, interview, and documentation. Analysis of data used with the process of data collection, data reduction, data presentation, and conclusion. From the research result level Technopreneurship of UMKM Sambel Pecel Wahyu Tumurun at level 5 and level 4. At level 5 includes appropriate technology assistance, documentation of production process, introduction of alternative process technology, introduction of market expansion and improvement of business efficiency and productivity, assistance to improve new technology access capability, utilization of technology in product design / design process, improvement of innovation climate among staff. At level 4 includes funding of technology utilization, technology audit, mentoring and training on UMKM is more emphasized on improvement of product research and development capability.
\end{abstract}

Keywords: Technopreneurship, UMKM, Wahyu Tumurun.

\begin{abstract}
Abstrak
Kota Madiun merupakan salah satu kota yang berada di wilayah Jawa Timur yang memiliki makanan khas yaitu "Sambel Pecel". Salah satu sambel pecel yang paling terkenal di Kota Madiun adalah sambel pecel Wahyu Tumurun. UMKM sambel pecel Wahyu Tumurun termasuk salah satu produk unggulan kota Madiun. Perlu adanya analisis tingkat technopreneursip pada UMKM sambel pecel Wahyu Tumurun Kota Madiun agar dapat meningkatkan hasil dan pengembangan kualitas dari usaha yang dijalani, sehingga mampu bersaing di pasar global. Penelitian dilakukan dengan menggunakan metode penelitian deskriptif kualitatif. Teknik pengumpulan data dilakukan dengan cara observasi, wawancara, dan dokumentasi. Analisis data yang digunakan dengan proses pengumpulan data, reduksi data, penyajian data, dan penarikan kesimpulan. Dari hasil penelitian tingkat Technopreneurship UMKM Sambel Pecel Wahyu Tumurun pada tingkat 5 dan tingkat 4 . Pada tingkat 5 meliputi bantuan teknologi tepat guna, dokumentasi proses produksi, pengenalan alternatif teknologi proses, pengenalan perluasan pasar dan peningkatan efisiensi dan produktifitas usaha, pendampingan untuk meningkatkan kemampuan akses teknologi baru, pemanfaatan teknologi dalam proses desain/perancangan produk, peningkatan iklim inovasi di kalangan staf. Pada tingkat 4 meliputi bantuan dana pemanfaatan teknologi, audit teknologi, pendampingan dan pelatihan pada UMKM ini lebih ditekankan pada peningkatan kemampuan penelitian dan pengembangan produk.
\end{abstract}

Kata Kunci: Technopreneurship, UMKM, Wahyu Tumurun 


\section{PENDAHULUAN}

Keterkaitan antara teknologi, kewirausahaan dan pertumbuhan Usaha Mikro, Kecil dan Menengah pada suatu perekonomian telah lama dikaji dalam literaturliteratur bisnis, manajemen dan ekonomi. Di dalamnya merefleksikan globalisasi dan pentingnya keterampilan kewirausahaan yang berwawasan kreativitas dan teknologi tinggi. Dalam hal ini, technopreneurship merupakan solusi untuk mencapai keunggulan kompetitif pada masa kini dimana permasalahan-permasalahan perekonomian berhubungan erat dengan persaingan. Untuk itu, diperlukan kombinasi antara teknologi beserta keseluruhan elemen-elemen kewirausahaan yang dikembangkan menjadi konsep "technopreneurship" yang mengacu pada perusahaan baru atau perusahaan prospektif yang terhubung dengan teknologi (Dutse, Ningi, Abubaka: 2013).

Sambel Pecel Wahyu Tumurun adalah UMKM yang terkenal di Kota Madiun yang terkenal dengan sambel pecel. Berdasarkan observasi awal menurut pemilik yang ibu danuk bahwa sambel pecel telah mewakili kota Madiun untuk EXPO ke daerah-daerah di Indonesia sebagai makanan khas sambel pecel yang bercita rasa khas Kota Madiun.

Menurut Michael E. Porter, daya saing suatu bangsa diindikasikan oleh jumlah produk berada di pasar Internasional melalui keunggulan inovasi dan ilmu pengetahuan, tidak pada melimpahnya Sumber Daya Alam (SDA) dan tenaga kerja yang murah. Permasalahan yang muncul, terdapat banyak sekali produk ekspor Indonesia yang ditolak karena kualitas produk. Kualitas produk terkait dengan kualitas SDM (Sumber Daya Manusia) dan kecanggihan pengelolaan produk. Penelitian Situmorang (2008) juga mengungkapkan beberapa masalah yang dapat menghambat UMKM di Indonesia, antara lain: (a) kurangnya permodalan, (b) kesulitan dalam pemasaran, (c) struktur organisasi sederhana dengan pembagian kerja yang tidak baku, (d) kualitas manajemen rendah, (e) kualitas SDM yang rendah, (f) tidak memiliki laporan keuangan, (g) legalitas lemah, dan (h) aspek teknologi rendah.

Rendahnya teknologi yang digunakan UMKM sambel pecel Wahyu Tumurun digambarkan melalui proses produksi secara manual. Hal ini mengakibatkan kualitas produk yang tidak terstandar, dan rendahnya kuantitas produk yang dapat dihasilkan. Hal ini tentu saja mengakibatkan UMKM tidak dapat memenuhi kebutuhan pasar dan meraih peluang pasar yang luas.

Dalam HELTS (Higher Education Long Term Strategy) dijelaskan bahwa "technopreneur" merupakan solusi untuk meningkatkan daya saing bangsa. Menurut Sosrowinarsidiono (2010), technopreneurship merupakan proses sinergi dari kemampuan yang kuat pada penguasaan teknologi serta pemahaman menyeluruh tentang konsep kewirausahaan (Sosrowinarsidiono, 2010). Dapat dikatakan bahwa technopreneur merupakan "entrepreneurmodern" berbasis teknologi. Teknologi tidak harus selalu high-tech, karena beberapa teknologi yang ditawarkan dengan otomatis dan canggih membutuhkan modal yang besar. Berdasarkan penelitian Sukardi (2015), UMKM merintis usaha dengan modal terbatas memiliki masalah terkait teknologi antara lain mahalnya harga alat baru (20\%), alat pengiris manual (10\%), kapasitas produksi rendah $(10 \%)$, dan menimbulkan sakit setelah penggunaan alat $(8,89 \%)$. Hal ini menunjukkan bahwa UMKM membutuhkan teknologi tepat guna dimana teknologi ini dirancang bagi UMKM sambel pecel yang sesuai dengan aspek-aspek lingkungan, sosial, budaya, dan ekonomi.

Sebagai salah satu UMKM di Kota Madiun yang terkenal adalah UMKM Sambel Pecel Wahyu Tumurun. UMKM Sambel 
Pecel Wahyu Tumurun yang beralamat J1. Timbangan No. 19, Banjarejo, Kota Madiun sebagai sentra industri sambel pecel khas Madiun. UMKM Sambel Pecel Wahyu Tumurun menjalankan produksi dengan pengolahan secara tradisional dan resep turun temurun, dan dengan tergantung salah satu personel sebagai pakar atau master. Namun, mereka masih memiliki kemauan dan kemampuan untuk berkembang dalam skala yang terbatas, sehingga peningkatan kemampuan teknologinya masih dapat ditingkatkan.

Penelitian ini bertujuan untuk menganalisis tingkat technopreneurship UMKM sambel pecel Wahyu Tumurun Kota Madiun. Sebagai salah satu yang berperan aktif dalam mengembangkan UMKM melalui penguatan sumber daya lokal.

\section{METODE PENELITIAN}

Jenis penelitian ini yaitu deskriptif kualitatif. Model penelitian ini mencari kebenaran fenomena di masyarakat untuk menganalisis tingkat technopreneurship pada
UMKM Wahyu Tumurun Kota Madiun. Lokasi penelitian dilaksanakan di Kota Madiun dengan rancangan waktu penelitian 6 bulan. Subyek penelitian adalah sambel pecel Wahyu Tumurun di Kota Madiun dengan sumber data primer dan data sekunder yang mendukung.

Teknik pengumpulan data dalam penelitian ini melalui, observasi, dan analisis dokumen. Teknik keabsahan data dengan menggunakan model trianggulasi sumber dan teknik analisis interaktif Miles dan Huberman.

\section{HASIL DAN PEMBAHASAN}

Deskripsi mengenai technopreneurship sambel pecel Wahyu Tumurun Kota Madiun, penelitian dilakukan dengan menggunakan metode penelitian deskriptif kualitatif. Melakukan pada 10 informan yang merupakan technopreneur sambel pecel Wahyu Tumurun Kota Madiun dan pengamatan untuk mendalami dan meneliti fenomena serta wawasan yang lebih jelas.

Tabel 1. Deskripsi Technopreneur Sambel Pecel Wahyu Tumurun Kota Madiun

\begin{tabular}{|c|c|c|}
\hline No & Pernyataan & Hasil \\
\hline 1 & Usaha & $\begin{array}{l}\text { Informan menyatakan usaha diperoleh } \\
\text { melalui keluarga, dan dengan metode ATM }\end{array}$ \\
\hline 2 & Lama berbisnis & Lama menjalankan usaha selama 3-6 tahun \\
\hline 3 & Deskripsi barang dan jasa & Teknologi informasi dan barang. \\
\hline 4 & Pangsa pasar & $\begin{array}{l}\text { Swasta, Instansi pemerintah dan juga } \\
\text { masyarakat umum }\end{array}$ \\
\hline 5 & Pesaing & $\begin{array}{l}\text { Para pesaing yang dihadapi informan adalah } \\
\text { bidang usaha sejenis dengan pemiliknya } \\
\text { adalah UKM sambel pecel di Kota Madiun } \\
\text { dan sekitarnya dan skala usaha yang lebih } \\
\text { besar. }\end{array}$ \\
\hline 6 & Diferensiasi produk atau jasa & $\begin{array}{l}\text { Belum mendiferensiasikan produk atau } \\
\text { jasanya dengan lebih rinci melalui produk, } \\
\text { merk, kemasan, ukuran dan rasa }\end{array}$ \\
\hline 7 & Perubahan produk berkala & Belum \\
\hline 8 & Iklan/Advertising & Media cetak dan Ekspo. \\
\hline
\end{tabular}


Bentuk penghargaan

11 Latar belakang pendidikan, pengetahuan dan pengalaman

12 Pembiayaan pada saat memulai usaha dan pada saat akan melakukan ekspansi usaha

$$
\text { Orientasi Ekspor }
$$

$$
\text { Pembaruan Teknologi }
$$$$
\text { Kondisi Perekonomian }
$$

Akses pemodalan, riset, dukungan dari pihak dan lembaga terkait serta pemecahan masalah

Fleksibel dan mandiri

Berpengaruh

Mandiri

Belum Ada

Belum

Berpengaruh
Dalam analisis tingkat kemampuan UMKM Sambel Pecel Wahyu Tumurun dapat dikelompokkan ke dalam 6 tingkat technopreneurship meliputi: 1) produsen teknologi;2) manajer teknologi; 3) konsumen teknologi; 4) sadar teknologi; 5) tidak sadar teknologi; 6) puas terhadap capaian saat ini. Hasil analisis tingkat kemampuan UMKM Sambel Pecel Wahyu tumurun dari informaninforman dan data yang diperoleh ditunjukkan dengan tabel sebagai berikut:

\begin{tabular}{|c|c|c|c|c|c|c|}
\hline \multirow{2}{*}{ Strategi } & \multicolumn{6}{|c|}{ Tingkat Technopreneurship } \\
\hline & 1 & 2 & 3 & 4 & 5 & 6 \\
\hline Peningkatan pengetahuan masyarakat & - & - & - & - & $\mathrm{V}$ & - \\
\hline Bantuan dana pemanfaatan teknologi & - & - & - & $\mathrm{v}$ & - & - \\
\hline Bantuan teknologi tepat guna & - & - & - & - & $\mathrm{v}$ & - \\
\hline Dokumentasi proses produksi & - & - & - & - & $\mathrm{v}$ & - \\
\hline Pengenalan alternatif teknologi proses & - & - & - & - & $\mathrm{v}$ & - \\
\hline $\begin{array}{l}\text { Pengenalan perluasan pasar dan peningkatan } \\
\text { efisiensi dan produktifitas usaha }\end{array}$ & - & - & - & - & $\mathrm{v}$ & - \\
\hline Audit teknologi & - & - & - & $\mathrm{v}$ & - & - \\
\hline $\begin{array}{l}\text { Pendampingan untuk meningkatkan kemampuan } \\
\text { akses teknologi baru }\end{array}$ & - & - & - & - & $\mathrm{v}$ & - \\
\hline $\begin{array}{l}\text { Pendampingan dan pelatihan pada UMKM ini } \\
\text { lebih ditekankan pada peningkatan kemampuan } \\
\text { penelitian dan pengembangan produk }\end{array}$ & - & - & - & $\mathrm{v}$ & - & - \\
\hline $\begin{array}{l}\text { Pemanfaatan teknologi dalam proses desain/ } \\
\text { perancangan produk }\end{array}$ & - & - & - & - & $\mathrm{v}$ & - \\
\hline Peningkatan iklim inovasi di kalangan staf & - & - & - & - & $\mathrm{v}$ & - \\
\hline $\begin{array}{l}\text { Peningkatan kemampuan mengelola asset } \\
\text { teknologi dan menilai teknologi sebagai bagian } \\
\text { dari pengelolaan resiko }\end{array}$ & - & - & - & - & - & - \\
\hline Insentif resiko ke gagalan teknologi & - & - & - & - & - & - \\
\hline Penjaminan dan standarisasi kualitas produk & - & - & - & - & - & - \\
\hline Percepatan alih teknologi melalui HKI & - & - & - & - & - & - \\
\hline
\end{tabular}

Tabel 2. Tingkat Kemampuan Technopreneurship UMKM Sambel Pecel Wahyu Tumurun 
Dari hasil tabel 2 di atas bahwa tingkat Technopreneurship UMKM Sambel Pecel Wahyu Tumurun pada tingkat 5. Peningkatan kemampuan pada Technopreneurship UMKM Sambel Pecel Wahyu Tumurun tingkat 5 diawali dengan pendokumentasian proses produksi untuk mengurangi ketergantungan terhadap sang master. Dokumentasi dapat dilakukan oleh keturunan (anak atau cucu) sang master. Langkah berikutnya adalah dengan mengikutsertakan mereka dalam beberapa pelatihan usaha agar mereka mengenal beberapa alternative teknologi proses dan didorong untuk mengaplikasikannya. Dampak pemanfaatan teknologi menyebabkan lingkungan kerja menjadi lebih bersih dan lebih hemat energi dibandingkan dengan teknologi yang lama. Teknologi yang dibutuhkan oleh UMKM Sambel Pecel Wahyu Tumurun adalah teknologi sederhana yang tidak membutuhkan dana besar dalam pengadaannya, sehingga stimulant dana yang dibutuhkan tidak besar. Strategi yang diterapkan UMKM Sambel Pecel Wahyu Tumurun berupa bantuan teknologi tepat guna serta pendampingan usaha. Melalui pendampingan tersebut mereka dikenalkan pada alternatifalternatif pasar yang lebih luas serta peningkatan efisiensi dan produktifitas usaha. Pendampingan juga diperlukan untuk menemukan titik-titik yang memungkinkan untuk diperbaiki dengan memanfaatkan teknologi baru yang lebih sesuai dengan lingkungan sekitar.

\section{PENUTUP}

\section{Simpulan}

Teknologi telah berkembang menjadi sumber kekuatan dan pengendali untuk bersaing. Sebagai sumber kekuatan, teknologi dapat dimanfaatkan dalam berbagai aktifitas bisnis, termasuk UMKM. Tingkat kemampuan UMKM Sambel Pecel Wahyu Tumurun dapat dikelompokkan ke dalam 6 tingkat technopreneurship meliputi: 1) produsen teknologi;2) manajer teknologi; 3) konsumen teknologi; 4) sadar teknologi; 5) tidak sadar teknologi; 6) puas terhadap capaian saat ini. Untuk tingkat Technopreneurship UMKM Sambel Pecel Wahyu Tumurun pada tingkat 5 dan tingkat 4. Pada tingkat 5 meliputi bantuan teknologi tepat guna, dokumentasi proses produksi, pengenalan alternatif teknologi proses, pengenalan perluasan pasar dan peningkatan efisiensi dan produktifitas usaha, pendampingan untuk meningkatkan kemampuan akses teknologi baru, pemanfaatan teknologi dalam proses desain/perancangan produk, peningkatan iklim inovasi di kalangan staf. Pada tingkat 4 meliputi bantuan dana pemanfaatan teknologi, audit teknologi, pendampingan dan pelatihan pada UMKM ini lebih ditekankan pada peningkatan kemampuan penelitian dan pengembangan produk.

\section{Saran}

Kemampuan teknologi dari UMKM sangat bervariasi dari yang tidak sadar teknologi sampai dengan produsen teknologi, untuk itu UMKM Sambel Pecel Wahyu Tumurun perlu melakukan Focus Group Discussion agar dapat mencari solusi bersama bagi masalah-masalahu usaha yang mereka hadapi. Perlu menjalin kerjasama dan dukungan berbagai pihak, seperti pemerintah, asosiasi usaha, perbankan agar turut serta meningkatkan pemberdayaan dan pengembangan melalui program-program dan pelatihan serta sosialisas yang akan meningkatkan daya saing UMKM. 


\section{DAFTARPUSTAKA}

Budiarto, Rachmawati. Dkk. 2015. Pengembangan UMKM Antara Konseptual dan Pengalaman Praktis. Yogyakarta: Gajah Mada University Press.

Depositario D.P.T., Aquino N.A., \& Feliciano K.C. 2011. Entrepreneurial Skill Development Needs Of Potential AgriBased Technopreneurs. ISSA AS, 17 (1): 106-120.

Dissanayake, B.D.M.P Bandara etal. 2015. Design and Development of a Low Cost Grain Flour Blender. The Institution of Engineers, Srilanka, Vol. XLVIII, No. 03, pp. [27-34].

Dutse, A.Y., Ningi., Abubakar. 2013. Technopreneurship and Enterprise Growth in Nigeria: An Exploration into The Latent Role of Microfinance Banks. IOSR Journal of Business and Management, Vol. 12 (2). 25-32.
Egge, K., Tan, W., and Mohamed, O. 2003. Boosting Technopreneurship through Business Plan Contests: Malaysia's venture 2001 \& 2002 competitions. Hawaii International Conference on Business: June 18-20, 2003.

H.B. Sutopo. 2006. Metodologi Penelitian Kualitatif. Surakarta. Universitas Sebelas Maret.

Jusoh, M. Abdullah dan Hazianti Abdul Halim. 2006. Role of Technopreneurs in Malaysian Economic, Journal of Global Business Management Vol. 2 No. 2, August 2006.

Lumpkin, G.T., and Dess, G.G. 2001. Linking Two Dimensions of Entrepreneurial Orientation to Firm Performance: The Moderating Role of Environment and Industry Life Cycle. Journal of Business Venturing, 16(5), 429- 451.

Miles dan Huberman. 1992. Analisis Data Kualitatif. Terjemahan Oleh Tjetjep Rohendi Rohidi. 2009. Jakarta : Universitas Indonesia. 